\title{
What is the Prevalence of Radiographic Hip Findings Associated With Femoroacetabular Impingement in Asymptomatic Asian Volunteers?
}

\author{
Taesoo Ahn MD, Chul-Ho Kim MD, Tae Hyung Kim MD, Jae Suk Chang MD, PhD, \\ Mi Yeon Jeong RN, Kekatpure Aditya DNB, Pil Whan Yoon MD, PhD
}

Received: 26 March 2016/ Accepted: 29 July 2016/Published online: 9 August 2016

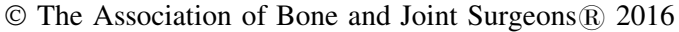

\begin{abstract}
Background Morphologic features of the proximal femur reminiscent of those seen in patients with femoroacetabular impingement (FAI) have been reported among asymptomatic individuals in Western populations, but whether this is the case in Asian populations is unknown.

Questions/purposes The purpose of this study was to determine the prevalence of radiographic findings in the proximal femur that are consistent with FAI in asymptomatic Korean volunteers.

Methods Two hundred asymptomatic volunteers with no prior hip surgery or childhood hip problems underwent three-view plain radiographs (pelvis AP view, Sugioka view, and $45^{\circ}$ Dunn view) of both hips. There were 146 hips from male volunteers and 254 hips from female volunteers in the study. The mean age of all participants was 34.7 years (range, 21-49 years). Cam-type morphologic

The institution of the authors has received funding from Hanmi Pharmaceutical Co, Ltd, Seoul, Korea.

Each author certifies that he or she has no commercial associations (eg, consultancies, stock ownership, equity interest, patent/licensing arrangements, etc) that might pose a conflict of interest in connection with the submitted article.

All ICMJE Conflict of Interest Forms for authors and Clinical Orthopaedics and Related Research ${ }^{\mathbb{R}}$ editors and board members are on file with the publication and can be viewed on request.

Each author certifies that his or her institution approved or waived approval for the human protocol for this investigation and that all investigations were conducted in conformity with ethical principles of research.
\end{abstract}

T. Ahn, C.-H. Kim, T. H. Kim, J. S. Chang, M. Y. Jeong,

K. Aditya, P. W. Yoon ( $\bowtie)$

Department of Orthopedic Surgery, Asan Medical Center,

University of Ulsan College of Medicine, 88, Olympic-ro, 43-gil,

Songpa-gu, Seoul 05505, South Korea

e-mail: orthoyoon@amc.seoul.kr features were defined as the presence of the following on one or more of the three views: pistol-grip morphologic features, an osseous bump at the femoral head-neck junction, flattening of the femoral head-neck offset, or alpha angle greater than $55^{\circ}$. Pincer-type morphologic features were determined by radiographic signs, including crossover sign, deficient posterior wall sign, or lateral centeredge angle greater than $40^{\circ}$.

Results The prevalence of cam-type morphologic features seen on at least one radiograph was 38\% (male, 57\%; female, 26\%). The prevalence of cam-type features (at least one positive cam-type feature) was $2.0 \%$ (male, 6\%; female, $0 \%$ ) on the pelvic AP view, 24\% (male, 36\%; female, 17\%) on the Sugioka view, and 30\% (male, 47\%; female, 20\%) on the $45^{\circ}$ Dunn view. The prevalence of pincer-type morphologic features (at least one positive pincer-type feature) was $23 \%$ (male, $27 \%$; female, $21 \%$ ) on the pelvic AP view.

Conclusion The prevalence of FAI-related morphologic features in asymptomatic Asian populations was comparable to the prevalence in Western populations. Considering the high prevalence of radiographic hip findings reminiscent of FAI in asymptomatic Asian populations, it will be important to determine whether FAIrelated morphologic features are a cause of hip pain when considering surgery in Asian patients.

\section{Introduction}

Femoroacetabular impingement (FAI) is a topic of substantial interest. Considered to be an important cause of hip pain in young adults, FAI has been reported as a potential cause of early osteoarthritis of the hip [14]. FAI typically is 
described as occurring as the result of asphericity of the femoral head (cam-type), overcoverage of the acetabulum (pincer type), or as a mixed type. However, the diagnosis is often difficult, and radiographic evaluation is controversial. FAI-related findings seen on plain radiographs include pistol-grip features, increased alpha angle, decreased femoral version, crossover sign, and increased center-edge angle. Although these morphologic features may cause pain and dysfunction in some hips, many hips remain asymptomatic, despite radiographic evidence of the FAIrelated features [38]. This had led many clinicians to question the prevalence of FAI-related morphologic features in asymptomatic individuals $[5,10,17,22,23$, 26, 27]. Studies from Western countries have reported a relatively high prevalence of these findings - up to $66 \%$ $[5,10,17,22,23,26,27,29]$. Based on these studies, the emphasis is shifting to careful and prudent selection of surgical candidates for FAI. Many clinicians agree that FAI is a clinical diagnosis and treatment decisions should not be made based on radiographic findings alone $[2,29,32,33$, $36,39]$.

The prevalence of asymptomatic FAI-related features in Asian populations is less-well studied, and previous studies report conflicting results, with prevalence ranging from $0.6 \%$ to $50 \%[12,21,25,30,44]$. Moreover, some of these studies involve data from tests that were performed owing to problems unrelated to the hip, and it is unknown whether study participants were truly asymptomatic [25, 30]. Studies regarding the prevalence of FAI in a proven asymptomatic cohort of Asian populations are lacking.

Therefore, in the current study, we tried to determine the prevalence of radiographic hip findings reminiscent of those seen in FAI in asymptomatic Asian volunteers.

We asked: (1) Is the prevalence of radiographic hip findings reminiscent of FAI in asymptomatic Asian volunteers different from those reported in other populations? (2) Are the patterns of FAI-related morphologic features detected on radiographs different between populations? (3) Are there sex-related differences in the patterns of radiographic hip findings reminiscent of FAI?

\section{Patients and Methods}

Our institutional review board approved this study. Between December 2014 and March 2015, 200 volunteers were recruited from our hospital, providing 400 hips. The inclusion criteria were: (1) age between 18 and 50 years, (2) no history of previous or ongoing pain related to the hip, and (3) no pain elicited on physical examination of the hip. The exclusion criteria were: (1) previous diagnosis of hip disorders, including Perthes disease, slipped capital femoral epiphysis, developmental dysplasia of the hip, arthritis of the hip, and hip fracture; (2) current hip-related pain such as groin or buttock pain; (3) previous surgery of the hip or pelvis; and (4) contraindication to radiographic imaging, such as pregnancy. Informed consent was acquired from all patients, and no compensation was offered. There were 200 asymptomatic volunteers (146 hips in male and 254 hips in female volunteers) included in our series. The mean age of all participants was 34.7 years (range, 21-49 years) (Table 1). All participants were nonathletes.

To confirm that all volunteers were asymptomatic, we performed a physical examination on each participant. Active and passive ROM (flexion, extension, internal and external rotation, abduction in $45^{\circ}$ flexion), Patrick test, and impingement test, were evaluated with all participants lying in the supine position. The Patrick test was performed with the tested hip flexed, abducted, and externally rotated, and it was checked if this position elicited groin pain. The impingement test was performed with the tested hip in flexion $\left(90^{\circ}\right)$, adduction, and internal rotation.

All participants underwent the following three-view series of plain radiographs: pelvic AP view, Sugioka view, and $45^{\circ}$ Dunn view of both hips. Pelvic radiographs were taken with patients in the supine position with a tube-tofilm distance of 40 inches $(102 \mathrm{~cm})$, with the tube perpendicular to the table. The crosshairs of the beam were centered on the point midway between the superior border of the pubic symphysis and a line drawn connecting the anterior superior iliac spines. The pelvic AP view was

Table 1. Baseline characteristics of the study population

\begin{tabular}{|c|c|c|c|c|}
\hline Characteristic & Male (146 hips) & Female (254 hips) & All volunteers (400 hips) & $\mathrm{p}$ Value \\
\hline Age (mean years, range) & $32(21-49)$ & $36(23-49)$ & $35(21-49)$ & $<0.001$ \\
\hline $\mathrm{BMI}$ (mean kg/m², range) & $25(20-33)$ & $21(17-30)$ & $23(17-33)$ & $<0.001$ \\
\hline Internal rotation $<20^{\circ}(\% /$ number $)$ & $30(44 / 146)$ & $2.8(7 / 254)$ & $13(51 / 400)$ & $<0.001$ \\
\hline Neck shaft angle (mean degrees, range) & $131(118-141)$ & $130(117-140)$ & $130(117-141)$ & 0.004 \\
\hline Joint space width (mean mm, range) & $4.0(2.4-7.2)$ & $3.9(1.1-6.4)$ & $4.0(1.1-7.2)$ & 0.494 \\
\hline Lateral center-edge angle (mean degrees, range) & $27(12-51)$ & $26(12-43)$ & $26(12-51)$ & 0.006 \\
\hline Sharp angle (mean degrees, range) & $38(32-44)$ & $41(31-49)$ & $40(31-49)$ & $<0.001$ \\
\hline
\end{tabular}


considered true when the coccyx tip and pubic symphysis were in line and the distance between them was between 1 and $3 \mathrm{~cm}$, and both teardrops, the iliac wing, and obturator foramen were symmetric. Both hips were internally rotated $15^{\circ}$ to $20^{\circ}$ to better evaluate femoral neck geometry [7]. Sugioka views were taken with the hip flexed to $90^{\circ}$ and abducted to $45^{\circ}$, and $45^{\circ}$ Dunn views were taken with the hip flexed to $45^{\circ}$ and abducted to $20^{\circ}$. With these views, information regarding the femoral head-neck junction can be obtained, especially on the anterior or anterolateral side [28].

All radiographs were reviewed by two experienced orthopaedic surgeons (PWY and THK) for the presence of FAI-related morphologic features. Cam-type morphologic features were defined as the presence of the following signs on one or more of the three views: pistol-grip features, an osseous bump at the femoral head-neck junction, flattening of the femoral head-neck offset, or alpha angle greater than $55^{\circ}$ (Fig. 1). A proximal femur with a severe aspheric head can resemble the "pistol grip", and other forms of camtype features may show flattening or a focal bump near the head-neck junction [20, 42]. The reviewers considered these signs to be either positive or negative. To evaluate the degree of asphericity, alpha angles were measured using the method of Nötzli et al. [35]. Although designed for use on CT or MR images, it is also a reliable and valid method for plain radiographs $[4,8,32]$. An imaginary circle was drawn that best fit the femoral head, and a line was drawn to connect the center of the femoral head and neck. A second line was drawn between the center of the femoral head and the point where the cortex of the femoral head exited the imaginary circle, and the angle between the two lines was measured. An alpha angle greater than $55^{\circ}$ was chosen as the reference value and considered to be the camtype pathologic feature $[25,43]$.

Pincer-type morphologic features were defined as the following signs on the pelvic AP view: crossover sign, deficient posterior wall sign, or lateral center-edge (LCE) angle greater than $40^{\circ}$. The crossover sign was considered positive if the line of the anterior wall crossed the line of the posterior wall before reaching the lateral edge of the sourcil. The deficient posterior wall sign was considered positive if the center of the femoral head was lateral to the posterior wall line. The LCE angle was measured using the following method: after drawing a reference line between the acetabular teardrops to correct for pelvic obliquity, a perpendicular line was drawn through the femoral head. A third line was drawn connecting the center of the femoral head to the superolateral sourcil. The angle made by the latter two lines was called the LCE angle [7].

Only cases considered positive by both observers were defined as true FAI-related morphologic features. The intraclass correlation coefficient (ICC) with 95\% CI was used to measure the interobserver and intraobserver agreements for continuous variables and the kappa statistic for dichotomous variables using SPSS Version 12.0 (SPSS Inc, Chicago, IL, USA). Observer agreement was considered slight if the ICC or kappa value was less than 0.21 , fair if it was 0.21 to 0.40 , moderate if it was 0.41 to 0.60 , substantial if it was 0.61 to 0.80 , and almost perfect if it
Fig. 1A-C (A) Pistol grip morphologic features, (B) an osseous bump on the anterosuperior aspect of the femoral neck (arrow head), and (C) flattening with bony sclerosis of the femoral head-neck junction (arrow) are shown.
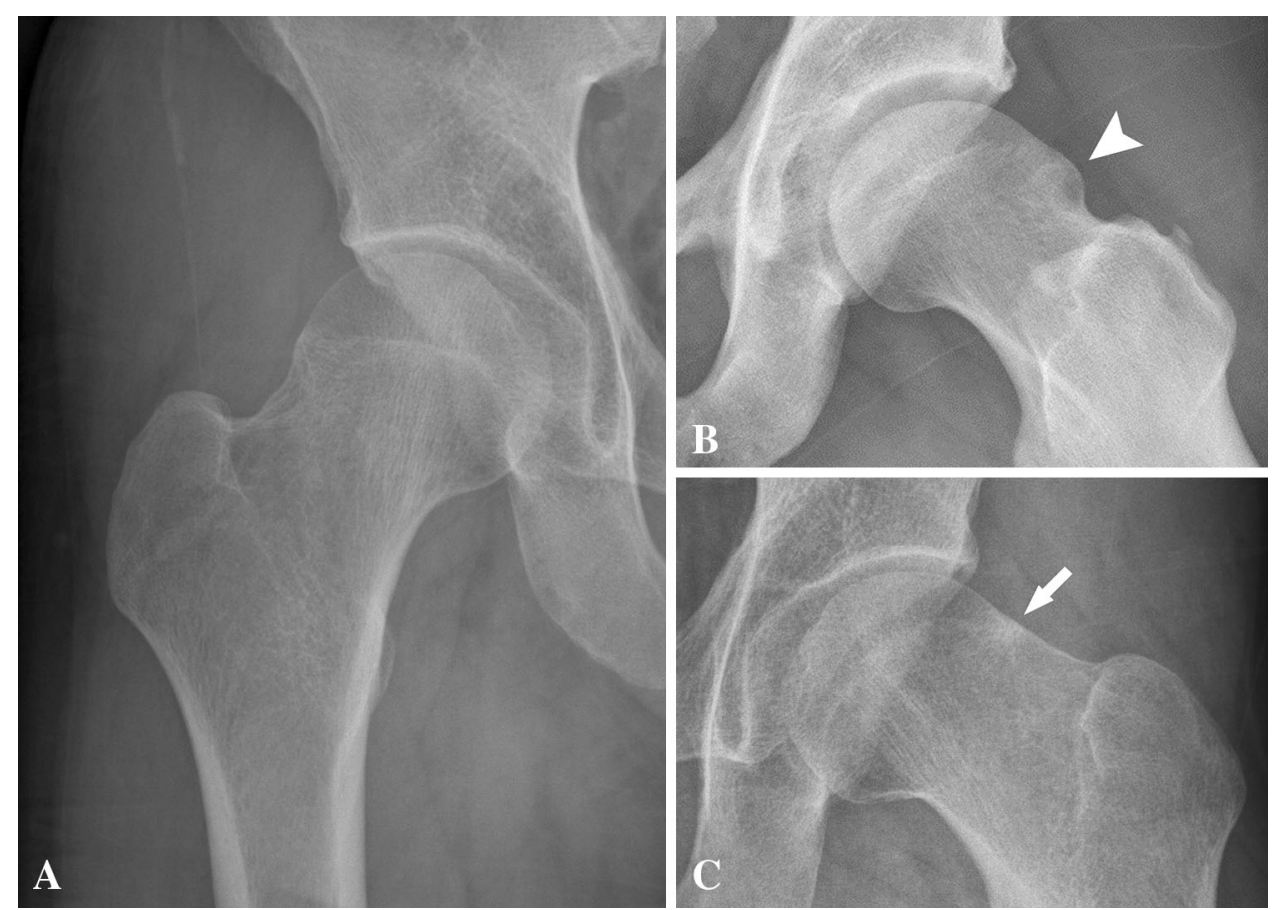
was greater than $0.80[8,24]$. Interobserver and intraobserver agreements were almost perfect for the LCE angle and alpha angle on all radiographs; substantial to almost perfect in rating cam-type and pincer-type morphologic features.

\section{Results}

On the pelvic AP view, the prevalence of pistol-grip morphologic features, bump, flattening, and an alpha angle greater than $55^{\circ}$ was $1.3 \%$ (male, $3.4 \%$; female, $0 \%$ ), $0.8 \%$ (male, $2.1 \%$; female, $0 \%$ ), $0.8 \%$ (male, $2.1 \%$; female, $0 \%$ ), and $0.5 \%$ (male, $1.4 \%$; female, $0 \%$ ), respectively (Table 2). On the Sugioka view, the prevalence of a bump, flattening, and an alpha angle greater than $55^{\circ}$ was $10 \%$ (male, $14 \%$; female, $7 \%$ ), $14 \%$ (male, $21 \%$; female, $9 \%$ ), and $5 \%$ (male, $12 \%$; female, $1.6 \%$ ), respectively. On the $45^{\circ}$ Dunn view, the prevalence of a bump, flattening, and an alpha angle greater than $55^{\circ}$ was $8 \%$ (male, $14 \%$; female, $4 \%$ ), $18 \%$ (male, $27 \%$; female, $12 \%$ ), and $8 \%$ (male, $16 \%$; female, $3.5 \%$ ), respectively (Table 3). The prevalence of a cam-type morphologic features observed on at least one radiograph was $38 \%$ (male, 57\%; female, 26\%). The prevalence of a cam-type morphologic features observed on two or more radiographs was $19 \%$ (male, $31 \%$; female, 13\%). The prevalence of a cam-type morphologic feature (at least one positive cam-type morphologic feature) was $2.0 \%$ (male, $6 \%$; female, $0 \%$ ) on the pelvic AP view, $24 \%$ (male, $36 \%$; female, $17 \%$ ) on the Sugioka view, and $30 \%$ (male, $47 \%$; female, $20 \%$ ) on the $45^{\circ}$ Dunn view. On the pelvic AP view, the prevalence of crossover sign, posterior wall sign, and LCE angle greater than $40^{\circ}$ was $20.0 \%$ (male, $23 \%$; female, $18 \%$ ), $21 \%$ (male, $23 \%$; female, $20 \%$ ), and $2.0 \%$ (male, $2.7 \%$; female, $1.6 \%$ ), respectively. The prevalence of a pincer-type FAI (at least one positive pincer-type morphologic feature) was $23 \%$ (male, $27 \%$; female, $21 \%$ ) on the pelvic AP view.

\section{Discussion}

Recently, the prevalence of FAI-related morphologic features in asymptomatic individuals was reported in an effort to better understand the condition and its possible link to hip osteoarthritis [9]. However, there is a paucity of longitudinal data regarding FAI, and the eventual fate of these lesions remain uncertain in many patients who have them [38]. Establishment of the prevalence of FAI-related

Table 2. Prevalence of FAI-related morphologic features observed on the pelvic AP view

\begin{tabular}{llll}
\hline Radiographic findings & Male & Female & All volunteers \\
\hline Cam-type morphologic features & & & \\
Pistol grip morphologic features & $3.4 \%$ & $0 \%$ & $1.3 \%$ \\
Bump & $2.1 \%$ & $0 \%$ & $0.8 \%$ \\
Flattening & $2.1 \%$ & $0 \%$ & $0.8 \%$ \\
Alpha angle $>55^{\circ}$ & $1.4 \%$ & $0 \%$ & $0.5 \%$ \\
Pincer-type morphologic features & & & \\
Crossover sign & $23 \%$ & $18 \%$ & $20 \%$ \\
Posterior wall sign & $23 \%$ & $20 \%$ & $21 \%$ \\
Lateral center-edge angle $>40^{\circ}$ & $2.7 \%$ & $1.6 \%$ & $2.0 \%$ \\
\hline
\end{tabular}

Table 3. Prevalence of FAI-related morphologic features on lateral radiographic views

\begin{tabular}{llll}
\hline Radiographic findings & Male & Female & All volunteers \\
\hline Sugioka view & & & $10 \%$ \\
Bump & $14 \%$ & $7 \%$ & $14 \%$ \\
Flattening & $21 \%$ & $9 \%$ & $5 \%$ \\
Alpha angle $>55^{\circ}$ & $12 \%$ & $1.6 \%$ & $8 \%$ \\
$45^{\circ}$ Dunn view & & & $18 \%$ \\
Bump & $14 \%$ & $4.3 \%$ & $8 \%$ \\
Flattening & $27 \%$ & $12 \%$ & $3.5 \%$ \\
Alpha angle $>55^{\circ}$ & $16 \%$ & & \\
\hline
\end{tabular}


morphologic features may be the first step to elucidating its natural history. A high prevalence of asymptomatic FAIrelated features has been reported in Western populations $[5,10,17,22,23,26,27]$, but no clear consensus has been reached in Asian populations [12, 21, 25, 30, 31, 44]. Previous studies of Western populations $[5,10,17,22$, $23,26,27]$ reported a prevalence of $14 \%$ to $66 \%$, with the prevalence varying according to the imaging method, population (such as an unselected population or a population consisting of athletes), sex of those analyzed, and morphologic features of interest (cam, pincer, or all types). Our results showed that the overall prevalence of FAIrelated morphologic features in the asymptomatic Korean population was $38 \%$ for cam-type and $23 \%$ for pincer-type lesions. These results are comparable to those of studies of Western populations $[5,10,17,23,26]$. The ability to detect these morphologic features appeared to increase when three radiographic views were used rather than a sole AP view, which is consistent with previous literature $[4,10,26]$.

Our study had some limitations. Our data were obtained from plain radiographs only, which might not be sensitive enough to detect all FAI-related morphologic abnormalities. The most sensitive method to detect FAI-related morphologic features would be axial and coronal images of the proximal femur obtained with CT or MRI. However, we could not expose asymptomatic volunteers to unnecessary radiation, nor could we perform MRI for all participants owing to its high cost. Radiographs are still the most popular method to evaluate patients with hip problems because they are simple to obtain and readily available. We believe that it is the most suitable method to screen for FAI-related morphologic features in most clinical settings. Another limitation of our study was that our cohort consisted of only Koreans and was too small to represent the entire Asian population. The fourth limitation was that exact reference values for alpha and LCE angles are not defined yet, and the prevalence rates may vary depending on the cutoff values. However, we believe that such factors are not significant enough to have influenced our major conclusions.

FAI has been suggested as a major cause of primary hip osteoarthritis [13, 14, 18, 39, 45, 46]. The prevalence of hip osteoarthritis is lower in Asian than in white populations $[19,34]$, and some authors have reported that the low prevalence of FAI-related morphologic features in Asian populations might explain this phenomenon [11, 21, 44]. However, recent studies, including ours, show the opposite $[25,30,31]$. Our findings cannot explain the discordance between the high rate of FAI-related morphologic features and low rate of hip osteoarthritis in Asian populations [6]. Based on our results, there is not enough evidence to prove the conventional theory that FAI-related morphologic features are a strong predisposing factor for hip osteoarthritis. There seem to be other factors that facilitate these features that actually cause impingement and development of hip osteoarthritis, although little is known about them [3, 39].

There have been few data for Asian populations regarding the prevalence of radiographic hip findings reminiscent of FAI, and most studies were on symptomatic patients $[12,31,44]$. Recent data based on CT images show a higher prevalence of FAI-related morphologic features in Asian patients with asymptomatic hips. Mimura et al. [30] investigated CT scans of 103 hips and found that $56.3 \%$ of hips had radiologic evidence of FAI-related morphologic features $(51.5 \%$ had an alpha angle greater than $50^{\circ}$ and $16.5 \%$ had negative acetabular anteversion). Kim et al. [25] retrospectively reviewed CT scans of 473 hips and concluded that $40 \%$ of the patients had at least one feature suggesting cam or pincer-type FAI ( $18 \%$ had an alpha angle $>55^{\circ}$ and $27 \%$ had an LCE angle $>40^{\circ}$ ). Both CT-based studies were performed with patients who had CT for conditions unrelated to hip disorders, however, it is unknown whether study participants were truly asymptomatic. Simple AP radiographs tend to show a lower prevalence of FAI (14\%-17\%), whereas CT or MR scans show higher rates (39\%-66\%) $[5,10,16,17,22,23]$. It is difficult to directly compare our results with those of Mimura et al. [30], because they used a $50^{\circ}$ cutoff value for the alpha angle to discriminate between cam and normal hips. With a cutoff value of $50^{\circ}$, an abnormal alpha angle was found in $14 \%$ on the Sugioka view and $28 \%$ on the $45^{\circ}$ Dunn view in our study participants. The prevalence of an alpha angle greater than $55^{\circ}$ in our study participants $(0.5 \%$ on the pelvic AP view, $5 \%$ on Sugioka view, and $8 \%$ on $45^{\circ}$ Dunn view) is lower than that reported by Kim et al. [25]. However, $38 \%$ of our participants showed positive FAIrelated findings on at least one of three radiographic views. A notable finding is that the overall prevalence rate in our study, based on simple radiographs, was comparable to that of CT scans. Use of multiple lateral views might have yielded such results. Cam-type lesions usually are found on the anterior or anterolateral side of the femoral head-neck junction, which are not observed on standard AP views. Cam-type morphologic features were seen most frequently on $45^{\circ}$ Dunn views, rather than Sugioka and pelvic AP views. This is consistent with the findings of previous studies that showed that the Dunn view is an effective method to detect cam-type morphologic features on the anterolateral side of the femur $[4,15]$. Our results also show that a three-view radiographic study may be sufficient, although not as sensitive as CT or MRI, to detect FAI-related morphologic features [32]. However MRI, in particular, is better suited to 
assess the comorbidities associated with FAI, including osteoarthritis, chondral labral delamination, and labral disorders [27].

Among the Western studies, similar results to ours was reported by Hack et al. [17], who reported a prevalence of $14 \%$ cam-type morphologic features in 200 asymptomatic volunteers (400 hips). All participants were recruited from their hospital and underwent physical examination to exclude patients with symptomatic hips. However, when confined to the 1:30 position of the femoral head-neck junction, the prevalence of an alpha angle greater than $50.5^{\circ}$ was $53 \%$, and $33.5 \%$ had an alpha angle greater than $55^{\circ}$. Reichenbach et al. [37] reported that $24 \%$ of 244 randomly selected asymptomatic military recruits had FAI. However, based on their grading, they counted only severe morphologic features as FAI, and it seems that many uncounted subjects had an alpha angle greater than $55^{\circ}$. If our current selection criteria were used, the prevalence rate would have been much higher. Both studies used MRI and looked for cam-type lesions only, in contrast to our analysis.

Cam-type morphologic features are more common in males. Agricola et al. [1] and Siebenrock et al. [40, 41] reported a higher incidence of cam-type morphologic features in male athletes and suggested that these features might be caused by vigorous sporting activities during the adolescent period. We also found a higher prevalence of cam-type morphologic features in male volunteers on all three radiographic views, and as much as $30 \%$ on $45^{\circ}$ Dunn views (47\% in males and $20 \%$ in females). Jung et al. [22] reported a cam-type prevalence of $14 \%$ in males and $6 \%$ in females on AP pelvic CT scout views of 755 hips. Similar to studies of other populations $[5,17,22,26]$, the prevalence of cam-type morphologic features was higher in males in the Korean population according to our results.

In asymptomatic Asian volunteers, the prevalence of observing cam-type morphologic features on AP pelvis radiographs is low, whereas the prevalence of observing cam-type morphologic features on Sugioka and $45^{\circ}$ Dunn views is comparable to that of previous Western studies and is higher in males. The prevalence of pincer-type morphologic features in asymptomatic Asian volunteers is also comparable to that of Western populations and is similar in both sexes. Considering the high prevalence of FAI morphologic features observed on plain radiographs in asymptomatic Asian populations, it will be important to determine whether FAI-related features are a cause of hip pain when considering surgery in Asian patients, or whether this simply represents an anatomic variant. Longterm studies will be of benefit in this regard. We intend to perform a longitudinal study using our cohort to establish whether an association exists between FAI-related morphologic features and development of hip osteoarthritis in Asian populations.

\section{References}

1. Agricola R, Heijboer MP, Ginai AZ, Roels P, Zadpoor AA, Verhaar JA, Weinans H, Waarsing JH. A cam deformity is gradually acquired during skeletal maturation in adolescent and young male soccer players: a prospective study with minimum 2year follow-up. Am J Sports Med. 2014;42:798-806.

2. Anderson SE, Siebenrock KA, Tannast M. Femoroacetabular impingement: evidence of an established hip abnormality. Radiology. 2010;257:8-13.

3. Bardakos NV, Villar RN. Predictors of progression of osteoarthritis in femoroacetabular impingement: a radiological study with a minimum of ten years follow-up. J Bone Joint Surg Br. 2009;91:162-169.

4. Barton C, Salineros MJ, Rakhra KS, Beaule PE. Validity of the alpha angle measurement on plain radiographs in the evaluation of cam-type femoroacetabular impingement. Clin Orthop Relat Res. 2011;469:464-469.

5. Chakraverty JK, Sullivan C, Gan C, Narayanaswamy S, Kamath S. Cam and pincer femoroacetabular impingement: CT findings of features resembling femoroacetabular impingement in a young population without symptoms. AJR Am J Roentgenol. 2013;200:389-395.

6. Cho HJ, Morey V, Kang JY, Kim KW, Kim TK. Prevalence and risk factors of spine, shoulder, hand, hip, and knee osteoarthritis in community-dwelling Koreans older than age 65 years. Clin Orthop Relat Res. 2015;473:3307-3314.

7. Clohisy JC, Carlisle JC, Beaule PE, Kim YJ, Trousdale RT, Sierra RJ, Leunig M, Schoenecker PL, Millis MB. A systematic approach to the plain radiographic evaluation of the young adult hip. J Bone Joint Surg Am. 2008;90(suppl 4):47-66.

8. Clohisy JC, Nunley RM, Otto RJ, Schoenecker PL. The frog-leg lateral radiograph accurately visualized hip cam impingement abnormalities. Clin Orthop Relat Res. 2007;462:115-121.

9. Collins JA, Ward JP, Youm T. Is prophylactic surgery for femoroacetabular impingement indicated? A systematic review. Am J Sports Med. 2014;42:3009-3015.

10. Diesel CV, Ribeiro TA, Scheidt RB, Macedo CA, Galia CR. The prevalence of femoroacetabular impingement in radiographs of asymptomatic subjects: a cross-sectional study. Hip Int. 2015;25:258-263.

11. Dudda M, Kim YJ, Zhang Y, Nevitt MC, Xu L, Niu J, Goggins J, Doherty M, Felson DT. Morphologic differences between the hips of Chinese women and white women: could they account for the ethnic difference in the prevalence of hip osteoarthritis? Arthritis Rheum. 2011;63:2992-2999.

12. Fukushima K, Uchiyama K, Takahira N, Moriya M, Yamamoto T, Itoman M, Takaso M. Prevalence of radiographic findings of femoroacetabular impingement in the Japanese population. $J$ Orthop Surg Res. 2014;9:25.

13. Ganz R, Leunig M, Leunig-Ganz K, Harris WH. The etiology of osteoarthritis of the hip: an integrated mechanical concept. Clin Orthop Relat Res. 2008;466:264-272.

14. Ganz R, Parvizi J, Beck M, Leunig M, Notzli H, Siebenrock KA. Femoroacetabular impingement: a cause for osteoarthritis of the hip. Clin Orthop Relat Res. 2003:417:112-120.

15. Goodman DA, Feighan JE, Smith AD, Latimer B, Buly RL, Cooperman DR. Subclinical slipped capital femoral epiphysis: relationship to osteoarthrosis of the hip. J Bone Joint Surg Am. 1997;79:1489-1497. 
16. Gosvig KK, Jacobsen S, Sonne-Holm S, Gebuhr P. The prevalence of cam-type deformity of the hip joint: a survey of 4151 subjects of the Copenhagen Osteoarthritis Study. Acta Radiol. 2008;49:436-441.

17. Hack K, Di Primio G, Rakhra K, Beaule PE. Prevalence of camtype femoroacetabular impingement morphology in asymptomatic volunteers. J Bone Joint Surg Am. 2010;92:2436-2444.

18. Harris WH. The correlation between minor or unrecognized developmental deformities and the development of osteoarthritis of the hip. Instr Course Lect. 2009;58:257-259.

19. Hoaglund FT, Oishi CS, Gialamas GG. Extreme variations in racial rates of total hip arthroplasty for primary coxarthrosis: a population-based study in San Francisco. Ann Rheum Dis. 1995;54:107-110.

20. Ito K, Minka MA 2nd, Leunig M, Werlen S, Ganz R. Femoroacetabular impingement and the cam-effect: a MRI-based quantitative anatomical study of the femoral head-neck offset. $J$ Bone Joint Surg Br. 2001;83:171-176.

21. Joo JH, Lee SC, Ahn HS, Park JS, Lee WJ, Jung KA. Evaluation of the alpha angle in asymptomatic adult hip joints: analysis of 994 hips. Hip Int. 2013;23:395-399.

22. Jung KA, Restrepo C, Hellman M, AbdelSalam H, Morrison W, Parvizi J. The prevalence of cam-type femoroacetabular deformity in asymptomatic adults. $J$ Bone Joint Surg $\mathrm{Br}$. 2011;93:1303-1307.

23. Kang AC, Gooding AJ, Coates MH, Goh TD, Armour P, Rietveld J. Computed tomography assessment of hip joints in asymptomatic individuals in relation to femoroacetabular impingement. Am J Sports Med. 2010;38:1160-1165.

24. Kapron AL, Anderson AE, Aoki SK, Phillips LG, Petron DJ, Toth R, Peters CL. Radiographic prevalence of femoroacetabular impingement in collegiate football players: AAOS Exhibit Selection. J Bone Joint Surg Am. 2011;93:e111

25. Kim J, Choi JA, Lee E, Lee KR. Prevalence of imaging features on $\mathrm{CT}$ thought to $\mathrm{Be}$ associated with femoroacetabular impingement: a retrospective analysis of 473 asymptomatic adult hip joints. AJR Am J Roentgenol. 2015;205:W100-105.

26. Laborie LB, Lehmann TG, Engesaeter IO, Eastwood DM, Engesaeter LB, Rosendahl K. Prevalence of radiographic findings thought to be associated with femoroacetabular impingement in a population-based cohort of 2081 healthy young adults. Radiology. 2011;260:494-502.

27. Lee AJ, Armour P, Thind D, Coates MH, Kang AC. The prevalence of acetabular labral tears and associated pathology in a young asymptomatic population. Bone Joint J. 2015;97:623-627.

28. Meyer DC, Beck M, Ellis T, Ganz R, Leunig M. Comparison of six radiographic projections to assess femoral head/neck asphericity. Clin Orthop Relat Res. 2006;445:181-185.

29. Miguel OF, Cabrita HB, Rodrigues MB, Croci AT. A comparative radiographic investigation of femoroacetabular impingement in young patients with and without hip pain. Clinics (Sao Paulo). 2012;67:463-467.

30. Mimura T, Kawasaki T, Itakura S, Hirata T, Fuzikawa H, Mori K, Imai S. Prevalence of radiological femoroacetabular impingement in Japanese hip joints: detailed investigation with computed tomography. J Orthop Sci. 2015;20:649-656.

31. Mori R, Yasunaga Y, Yamasaki T, Nakashiro J, Fujii J, Terayama $\mathrm{H}$, Ohshima S, Ochi M. Are cam and pincer deformities as common as dysplasia in Japanese patients with hip pain? Bone Joint J. 2014;96:172-176.

32. Nepple JJ, Martel JM, Kim YJ, Zaltz I, Clohisy JC; ANCHOR Study Group. Do plain radiographs correlate with CT for imaging of cam-type femoroacetabular impingement? Clin Orthop Relat Res. 2012;470:3313-3320.

33. Nepple JJ, Prather H, Trousdale RT, Clohisy JC, Beaulé PE, Glyn-Jones S, Kim YJ. Clinical diagnosis of femoroacetabular impingement. J Am Acad Orthop Surg. 2013;21(suppl 1):S16-19.

34. Nevitt MC, Xu L, Zhang Y, Lui LY, Yu W, Lane NE, Qin M, Hochberg MC, Cummings SR, Felson DT. Very low prevalence of hip osteoarthritis among Chinese elderly in Beijing, China, compared with whites in the United States: the Beijing osteoarthritis study. Arthritis Rheum. 2002;46:1773-1779.

35. Nötzli HP, Wyss TF, Stoecklin CH, Schmid MR, Treiber K, Hodler J. The contour of the femoral head-neck junction as a predictor for the risk of anterior impingement. J Bone Joint Surg Br. 2002;84:556-560.

36. Ranawat AS, Schulz B, Baumbach SF, Meftah M, Ganz R, Leunig M. Radiographic predictors of hip pain in femoroacetabular impingement. HSS J. 2011;7:115-119.

37. Reichenbach S, Juni P, Werlen S, Nüesch E, Pfirrmann CW, Trelle S, Odermatt A, Hofstetter W, Ganz R, Leunig M. Prevalence of cam-type deformity on hip magnetic resonance imaging in young males: a cross-sectional study. Arthritis Care Res (Hoboken). 2010;62:1319-1327.

38. Rubin DA. Femoroacetabular impingement: fact, fiction, or fantasy? AJR Am J Roentgenol. 2013;201:526-534.

39. Sankar WN, Nevitt M, Parvizi J, Felson DT, Agricola R, Leunig M. Femoroacetabular impingement: defining the condition and its role in the pathophysiology of osteoarthritis. $J$ Am Acad Orthop Surg. 2013;21(suppl 1):S7-15.

40. Siebenrock KA, Ferner F, Noble PC, Santore RF, Werlen S, Mamisch TC. The cam-type deformity of the proximal femur arises in childhood in response to vigorous sporting activity. Clin Orthop Relat Res. 2011;469:3229-3240.

41. Siebenrock KA, Kaschka I, Frauchiger L, Werlen S, Schwab JM. Prevalence of cam-type deformity and hip pain in elite ice hockey players before and after the end of growth. Am J Sports Med. 2013;41:2308-2313.

42. Stulberg SD. Unrecognized childhood hip disease: a major cause of idiopathic osteoarthritis of the hip. In: Cordell LD, Harris WH, Ramsey PL, MacEwen GD, eds. The Hip: Proceedings of the Third Open Scientific Meeting of the Hip Society. St Louis, MO: CV Mosby; 1975:212-228.

43. Sutter R, Dietrich TJ, Zingg PO, Pfirrmann CW. How useful is the alpha angle for discriminating between symptomatic patients with cam-type femoroacetabular impingement and asymptomatic volunteers? Radiology. 2012;264:514-521.

44. Takeyama A, Naito M, Shiramizu K, Kiyama T. Prevalence of femoroacetabular impingement in Asian patients with osteoarthritis of the hip. Int Orthop. 2009;33:1229-1232.

45. Tannast M, Goricki D, Beck M, Murphy SB, Siebenrock KA. Hip damage occurs at the zone of femoroacetabular impingement. Clin Orthop Relat Res. 2008;466:273-280.

46. Tanzer M, Noiseux N. Osseous abnormalities and early osteoarthritis: the role of hip impingement. Clin Orthop Relat Res. 2004;429:170-177. 